\title{
CORDEX - An international climate downscaling initiative
}

\author{
J.P. Evans ${ }^{1}$ \\ ${ }^{1}$ Climate Change Research Centre, University of New South Wales, Sydney, New South Wales \\ Email: jason.evans@unsw.edu.au
}

\begin{abstract}
The World Climate Research Programme (WCRP) is backing an international initiative called the COordinated Regional climate Downscaling EXperiment (CORDEX). The goal of the initiative is to provide regionally downscaled climate projections for most land regions of the globe, as a compliment to the global climate model projections performed within the fifth Coupled Model Intercomparison Project (CMIP5). CORDEX includes data from both dynamical and statistical downscaling. It is anticipated that the CORDEX dataset will provide a link to the impacts and adaptation community through its better resolution and regional focus. Participation in CORDEX is open and any researchers performing climate downscaling are encourage to engage with the initiative.
\end{abstract}

The model evaluation framework consists of RCM simulations performed using the European Centre for Medium-Range Weather Forecasts (ECMWF) ERA-Interim re-analysis (Uppala et al., 2008) as "perfect boundary conditions". These simulations will be evaluated through a set of regional benchmark statistics, against regional datasets, that are designed and assembled by regional diagnostic teams. The climate projection framework within CORDEX is based on the set of new GCM simulations currently underway in support of the IPCC fifth Assessment Report, referred to as CMIP5. CORDEX will focus on the GCM experiments using emission scenarios known as RCP4.5 and RCP8.5 which represent a mid and a high-level emission scenario. Ideally CORDEX simulations will span 1951 to 2100 though given the computational demand of such long transient runs a series of 30 year time slices is also possible. Each RCM should perform these simulations for multiple GCMs.

While CORDEX is focused on using CMIP5 simulations for boundary conditions, which are still being created by the GCM groups, NARCliM uses the same AustralAsia and south-east Australia domains to downscale CMIP3 simulations. One of the unique aspects of both the CORDEX and NARCliM databases will be the presence of many three hourly fields. This will allow investigations of the simulation of diurnal cycles in RCM ensembles that have not been previously possible.

Keywords: CORDEX, regional climate projections, regional climate modelling, CMIP5, AustralAsia 


\section{INTRODUCTION}

Future climate change has been recognised as one of the largest issues facing the world in the coming century. The Intergovernmental Panel on Climate Change (IPCC) has been tasked with compiling the state of knowledge in relation to climate change on a regular basis. To date they have produced four such assessments with the fifth due in 2013-2014. These assessments are the basis of knowledge used by most governments to establish climate change related policy including the ongoing debates around the introduction of a price on greenhouse gas pollution.

Global Climate Models (GCMs) are the main tools used to project the extent of this future climate change. The Coupled Model Intercomparison Project 3 (CMIP3, Meehl et al., 2007) was the international collaborative effort of GCM groups to produce projections that directly informed the IPCC fourth assessment report (IPCC, 2007). This database of global climate projections has been widely used to investigate global climate system processes (e.g. Diffenbaugh et al., 2008; de Szoeke and Xie, 2008) as well as large scale climate change projections (Marriotti et al., 2008; Evans, 2009a; Vavrus et al., 2009). This construction of a many GCM ensemble is vital for dealing with the uncertainty associated with future projections. Every GCM, that performs adequately for the recent past, provides a plausible projection of future climate and it is difficult to know which of these plausible futures is more likely. Hence the use of a many model ensemble is required to provide some measure of likelihood of the projected future climate.

As the risks associated with large scale climate change have become better understood, more impact and adaptation studies have been performed. A significant spatial scale problem exists between the scale of the GCMs (200-400km) and the scales of interest for impacts and adaptation studies which are often only tens of kilometres or less. In order to address this spatial scale problem various methods to downscale the GCM output have been developed. These downscaling methods can be generalised into two types: statistical and dynamical. Statistical downscaling involves deriving statistical relationships between some large scale predictors and the local variable of interest. An example would be to use the GCM predicted mean sea level pressure or $500 \mathrm{hPa}$ geopotential height to predict precipitation at a station location. It is then assumed that this statistical relationship remains true in a future changed climate and hence can be used to downscale both the present and the future climate. Dynamical downscaling uses mathematical representations of the physical processes that create the climate system, similar to GCMs, applied at a higher spatial resolution than the GCMs. In this way they are able to capture climate phenomena not resolved by the GCMs including the influence of mountains and coastlines. Dynamical downscaling is done with a Regional Climate Model (RCM). When downscaling future climate projections RCMs assume that the physical laws remain the same. Statistical downscaling techniques can also be applied to RCM output in order to provide information at point locations.

One advantage of statistical techniques is that they are less computationally intensive and hence can be used to downscale many GCM (or RCM) climate projections. This allows the statistical techniques to be applied to many climate models and hence they can span the range of plausible future climates. RCMs on the other hand, are quite computationally intensive and to date this has prevented them from being used to downscale many GCMs, hence they have not sampled the full range of plausible future climates. This issue has been addressed in a number of large international projects focused on Europe (PRUDENCE - Christensen and Christensen (2007), ENSEMBLES - van der Linden and Mitchell (2009)) and North America (NARCAP Mearns et al. (2009)) that produced large ensembles of RCM simulations. PRUDENCE was the first attempt to produce a RCM ensemble through a large cooperative international program. In this case several RCMs were used to downscale the same GCM thus providing a measure of the uncertainty associated with RCM simulations but not placing this within the context of plausible future climates simulated by GCMs (Deque et al., 2005). Both ENSEMBLES in Europe and NARCAP in North America, have attempted to address this issue by using a collection of RCMs to downscale a collection of GCMs. While these projects have found significant spread amongst the RCMs it has generally been smaller than the spread found in the full GCM ensemble (Fowler et al., 2007). Thus, an emphasis on sampling the GCM ensemble more comprehensively has been recommended (Kendon et al., 2010). 


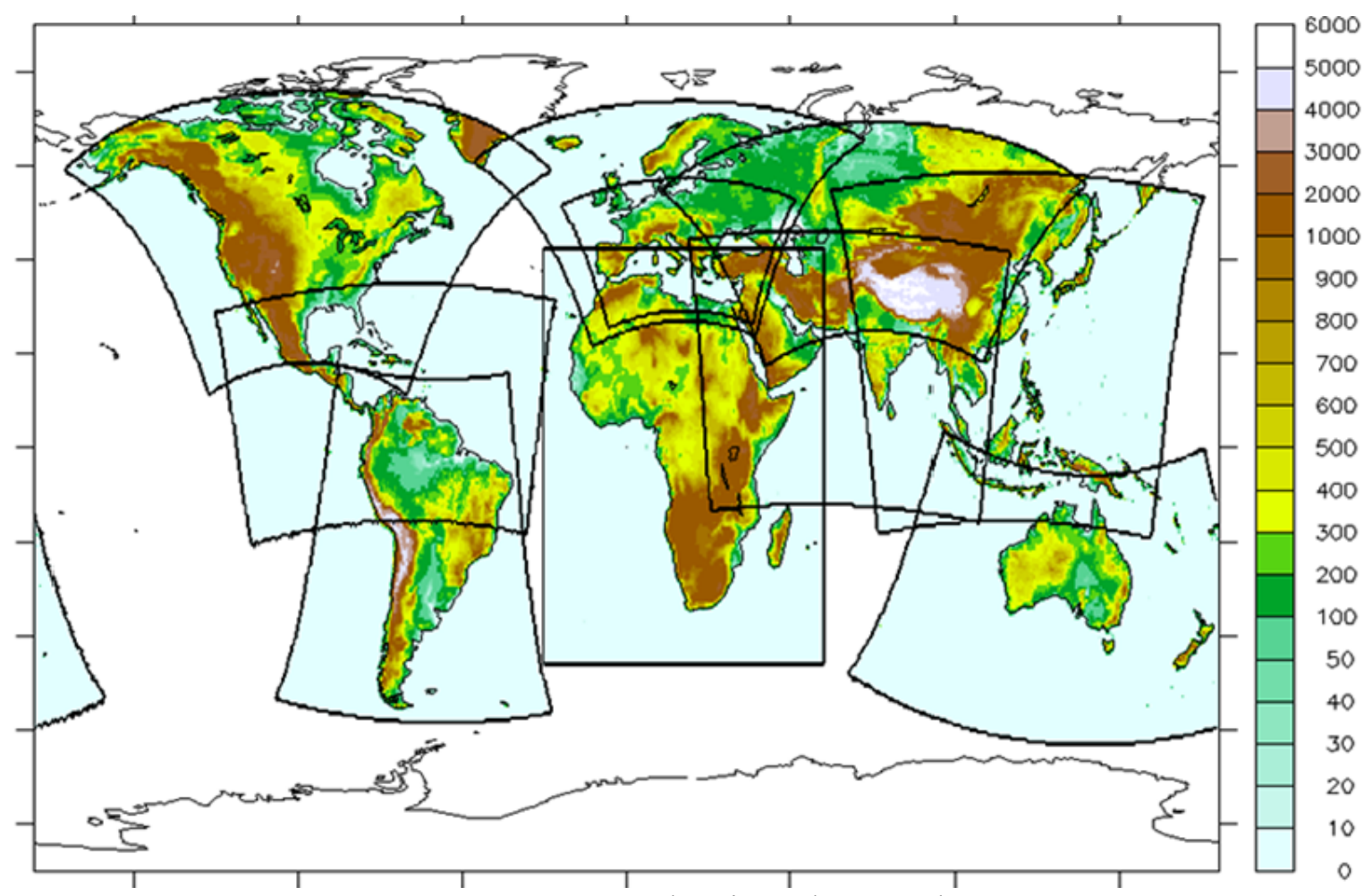

Figure 1: CORDEX domains and topography.

The COordinated Regional climate Downscaling Experiment (CORDEX) is a World Climate Research Program (WCRP) backed framework to produce ensembles of regional climate projections for all continents globally (Giorgi et al., 2009; http://wcrp.ipsl.jussieu.fr/SF_RCD_CORDEX.html). CORDEX will bring together regional scale climate projections produced using both statistical and dynamical techniques. It aims to provide a framework to evaluate and benchmark model performance as well as producing projections for use in impact and adaptation studies. The first part of this framework is a set of common regional domains. These domains are shown in Figure 1. There is also an Arctic and an Antarctic domain. The AustralAsia CORDEX domain is shown in Figure 2. The model evaluation framework consists of RCM simulations performed using the European Centre for Medium-Range Weather Forecasts (ECMWF) ERA-Interim reanalysis (Uppala et al., 2008) as "perfect boundary conditions". These simulations will be evaluated through a set of regional benchmark statistics, against regional datasets, that are designed and assembled by regional diagnostic teams. The climate projection framework within CORDEX is based on the set of new GCM simulations currently underway in support of the IPCC fifth Assessment Report, referred to as CMIP5. CORDEX will focus on the GCM experiments using emission scenarios known as RCP4.5 and RCP8.5 which represent a mid and a high-level emission scenario. Ideally CORDEX simulations will span 1951 to 2100 though given the computational demand of such long transient runs a series of 30 year time slices is also possible. Each RCM should perform these simulations for multiple GCMs.

The regional benchmark statistics will include both general comparisons of observed and modelled variables, as well as metrics aimed at particular phenomena such as the onset and evolution of the monsoon. Many studies have looked at various aspects of the climate system to evaluate RCMs, often with a focus on temperature and precipitation as these are the best observed climate variables. For example, Evans et al. (2005) investigated the performance through time of many variables but only for a single grid point. Kostopoulou et al. (2009) looked at maximum and minimum temperature on a seasonal basis. Evans (2009) and Evans et al. (2004) used temperature and precipitation on climatological and monthly time scales. Salon et al. (2008) focused on precipitation at the monthly to annual time scale. Rummukainen et al. (2001) evaluated seasonal to annual temperature and precipitation as well as sea surface temperatures of the Baltic Sea. Solman et al. (2008) looked at seasonal means and cycles, inter-annual variability and extreme events in precipitation and surface air temperatures. While Evans and McCabe (2010) evaluated a RCM against precipitation and temperature at daily, monthly, inter-annual and multi-annual time scales including the representation of El Nino - Southern Oscillation (ENSO) and the impact of drought. In addition Druyan et al. (2010) evaluated the ability of some RCMs to simulate the West African Monsoon by looking at specific 


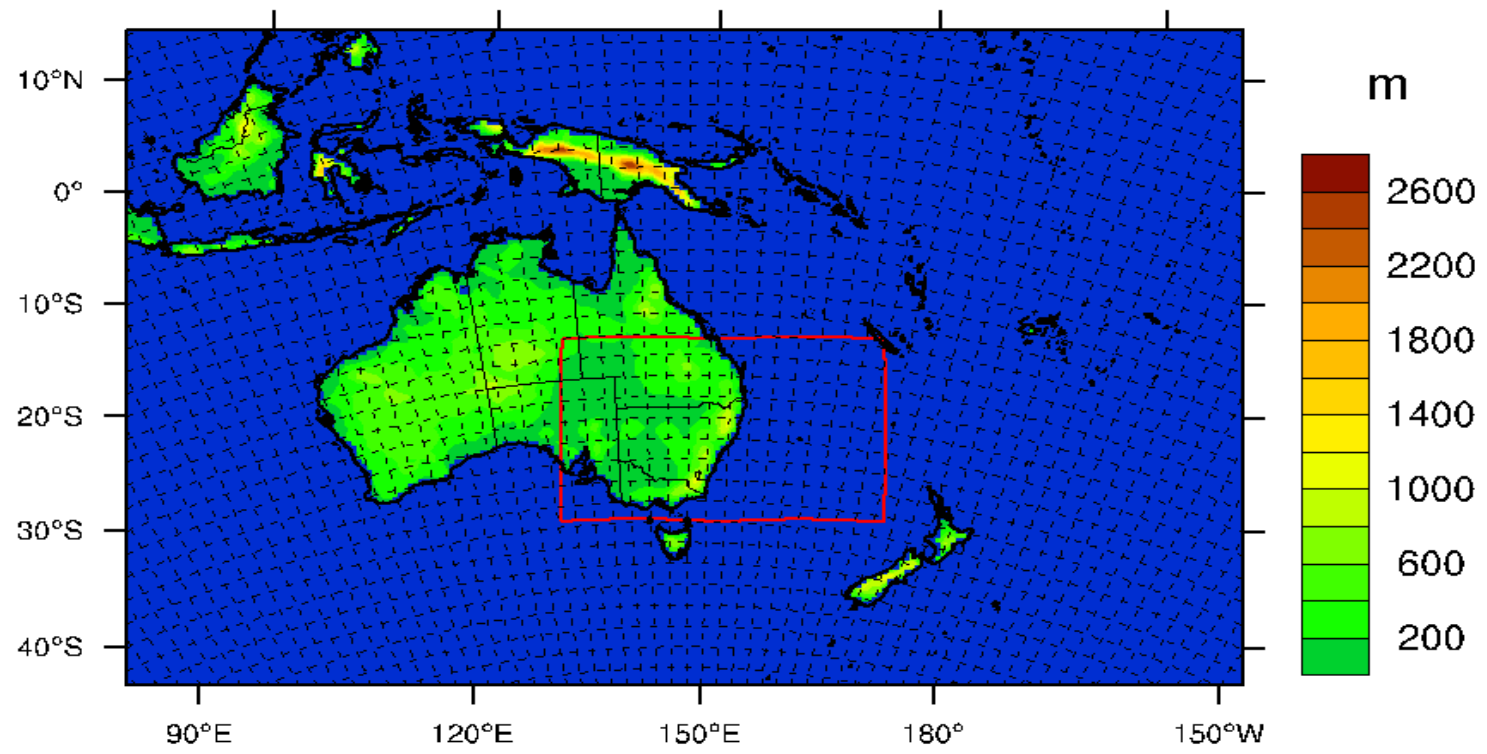

Figure 2: CORDEX AustralAsia domain and topography. The red rectangle outlines the high resolution south-east Australia sub-domain.

aspects of the system such as latitudinal progression of precipitation fields with season and the vertical cross section of zonal winds.

When studying future regional climate changes there are many different sources of uncertainty. Here these sources of uncertainty are broken down into three main sources, a different but similar way to categorise these sources of uncertainty can be found in Foley (2010). The first source, and one of the largest unknowns, is the future emissions of greenhouse gases. Since this is dependent on human activities and policy actions, the future evolution of greenhouse gas emissions is presented as a series of possible emission scenarios or projections. These scenarios are then used in GCM simulations to study the impact on climate. The GCM model physics and numerical structure are the second source of uncertainty. The last main source of uncertainty is the downscaling method itself. In the case of RCMs this includes the model physics and structure similar to issues associated with GCMs, while for statistical downscaling this includes uncertainties associated with the statistical technique used. In combination these sources of uncertainty provide a limit to the confidence that can be placed in any particular projection of future regional climate.

Quantifying this uncertainty is done by creating a collection, or ensemble, of climate simulations that sample various parts of the uncertainty described above. Emission scenario uncertainty is addressed by running simulations from more than one scenario. To quantify the uncertainty associated with GCMs an ensemble of many GCMs should be used and similarly for RCMs (or dynamical downscaling) many RCMs should also be used. Ideally these GCMs and RCMs would be independent of each other ensuring they are sampling from different parts of the plausible future climate space. Once an ensemble which samples these uncertainties has been established there are multiple methods for combining the information to establish a probabilistic future climate change prediction. Déqué and Somot (2010) used a technique that weights a frequency distribution based on model performance. Bayesian analysis has also been used in a number of ways (Tebaldi et al., 2004,2005; Buser et al., 2010) and is an area of active research.

\section{CORDEX AUSTRALASIA}

The CORDEX initiative is attempting to create RCM ensembles for 12 different regions around the globe (see Figure 1). There are many research groups around the world contributing to this initiative. Africa is the initial focus region and many groups are performing simulations for this region. After Africa most research groups are performing simulations for their home domain with other regions having a lower priority. For CORDEX-AustralAsia the "home" groups include a group at the Commonwealth Scientific and Industrial Research Organisation (CSIRO) and another at National Institute of Water and Atmospheric (NIWA) Research in New Zealand who are likely to contribute RCM simulations to the ensemble. In order for 
CORDEX-AustralAsia to be a success many more groups need to be encouraged to perform simulations for the AustralAsia domain. Coordination of these groups will also be provided to ensure the simulations performed are complimentary and do not simply duplicate each other.

Before any climate models can be used to project future climate their ability to simulate the climate of the recent past must be evaluated. While the ability to accurately simulate the recent past does not guarantee skill in simulating future climates, it provides a minimum benchmark for a model. That is, if a model cannot adequately simulate the recent past then one would have much lower confidence in its future projections compared to a model that can simulate the recent past well. Here the RCMs will be evaluated as comprehensively as possible. First they will be evaluated over Australia using precipitation and temperature observations at many time scales following Evans and McCabe (2010). This will test the RCM ability to capture climate dynamics at the daily to inter-annual time scales including their ability to capture the impacts of ENSO and droughts. They will then be evaluated for their ability to simulate the Australian monsoon using metrics similar to those used in recent West African Monsoon studies (e.g. Druyan et al., 2010). Many other evaluation metrics and variables have been investigated for the Australian region for GCMs (see Smith and Chandler (2010) for a summary). A regional diagnostics team will be formed with members of the "home" RCM teams, interested international collaborators and others who have established metrics previously to ensure that the evaluation is as comprehensive as possible.

When quantifying the projected future regional climate change a five step process is proposed. First, based on the evaluation results, any GCMs that perform particularly poorly will be removed from the analysis. Then the remaining models will be tested for independence by modifying the method of Bishop and Abramowitz (2011). A collection of those GCMs that demonstrate independence from other GCMs, and that span the plausible future climate space, will be used to downscale from. Thirdly, a similar process of evaluating the RCM performance, and removing any RCMs that perform unacceptably poorly will be undertaken. The remaining RCMs will be used to downscale the independent GCMs and this GCM/RCM ensemble will itself be tested for independence. This measure of independence will then be used to weight the ensemble mean and frequency distribution in a manner similar to Déqué and Somot (2010). The potential for using this measure of model independence to inform the prior distribution within a Bayesian approach will also be explored. Explicitly accounting for model independence (and hence their correlation) is one of the few remaining largely unexplored issues with regard to forming a statistically robust ensemble. Progress made in this regard will feed quickly back to inform the other CORDEX region ensembles.

While the CORDEX simulations are high resolution compared to the GCM simulations they are still $\sim 50 \mathrm{~km}$ resolution which remains too coarse for many impacts and adaptation studies. As such a sub-domain over south-east Australia (see Figure 2) is proposed to be run at $10 \mathrm{~km}$ resolution. Other similar sub-domains are also under consideration including south-west Australia and New Zealand.

Core data from all CORDEX domains will be stored on a central data server at the Danish Meteorological Institute (http://cordex.dmi.dk/joomla/). It is hoped that all AustralAsia data will also be stored and made available through a mirror site in Australia with discussions underway with the National Computational Infrastructure (NCI) supercomputer facility to host the data alongside the CMIP5 data.

\section{NSW/ACT REGIONAL CLIMATE MODELLING (NARCLIM) PROJECT}

While CORDEX is focused on using CMIP5 simulations for boundary conditions, which are still being created by the GCM groups, NARCliM uses the same AustralAsia and south-east Australia domains to downscale CMIP3 simulations. One of the unique aspects of both the CORDEX and NARCliM databases will be the presence of many three hourly fields. This will allow investigations of the simulation of diurnal cycles in RCM ensembles that have not been previously possible. Observational studies have found trends in hourly precipitation that do not meet standard expectations (Lenderink, and Van Meijgaard, 2008). Whether similar effects are modelled in RCMs will be investigated in a systematic fashion in this project. Alexander and Arblaster (2009) show regions of Australia that are projected to have larger daily precipitation extremes despite an overall decrease in precipitation. Thus there is some critical time scale at which the change in precipitation events transitions from a decrease to an increase. In order to explore this transition for shorter time scales the RCMs used in NARCliM will be amended to output hourly precipitation as well as the maximum 5, 10, 20, 30 and 60 minute precipitation totals each day. This will allow direct investigation of the climate change impact on these short time scale precipitation extremes for the first time. By evaluating these variables against the network of pluviometer measurements of precipitation in Australia, model problems simulating short time scale precipitation will be identified, the sensitivity to various physical parametrisations will be tested and amendments to improve these schemes developed. As these are the same time intervals used by flood engineers in their design storms, this analysis will be followed through to investigate the 
potential impact on flood design storms and hence the engineering of storm water drains and other infrastructure.

\section{SUMMARY}

CORDEX is an international initiative to create large regional climate projection ensembles for all the main land areas of the globe. CORDEX-AustralAsia is the domain covering Australia and New Zealand. All local or international regional climate modelling groups are encouraged to participate in providing simulations to the CORDEX-AustralAsia database. While regional climate modelling (dynamical downscaling) is a significant focus of CORDEX, statistical downscaling of CMIP5 results is also encouraged as a contribution to CORDEX.

While CORDEX is focused on downscaling the new CMIP5 GCM simulations, the NARCliM project is using the same domains to downscale the CMIP3 simulations. Together these projects will create a large regional scale climate projection ensemble that places the new CORDEX results in context of the well characterised CMIP3 driven projections.

\section{ACKNOWLEDGEMENTS}

The NARCliM project is funded and managed by the NSW Office of Environment and Heritage.

\section{REFERENCES}

Alexander, L. V., and J. M. Arblaster (2009), Assessing trends in observed and modelled climate extremes over Australia in relation to future projections, International Journal of Climatology, 29(3), 417-435.

Bishop, C.H., and G. Abramowitz (2011) Climate model dependence and the replicate Earth Paradigm, Journal of Climate, in review.

Christensen, J., and O. Christensen (2007), A summary of the PRUDENCE model projections of changes in European climate by the end of this century, Climatic Change, 81, 7-30, doi:10.1007/s10584-006-9210-7.

Christensen, J., E. Kjellstrom, F. Giorgi, G. Lenderink, and M. Rummukainen (2010), Weight assignment in regional climate models, Climate Research, 44(2-3), 179-194, doi:10.3354/cr00916.

CSIRO (2007), Climate Change in Australia, Technical Report, CSIRO. [online] Available from: http://www.climatechangeinaustralia.gov.au/index.php

de Szoeke, S., and S. Xie (2008), The tropical eastern Pacific seasonal cycle: Assessment of errors and mechanisms in IPCC AR4 coupled ocean - Atmosphere general circulation models, Journal of Climate, 21(11), 2573-2590, doi:10.1175/2007JCLI1975.1.

Deque, M. et al. (2005), Global high resolution versus Limited Area Model climate change projections over Europe: quantifying confidence level from PRUDENCE results, Climate Dynamics, 25(6), 653-670, doi:10.1007/s00382-005-0052-1.

Deque, M., and S. Somot (2010), Weighted frequency distributions express modelling uncertainties in the ENSEMBLES regional climate experiments, Climate Research, 44(2-3), 195-209, doi:10.3354/cr00866.

Diffenbaugh, N., F. Giorgi, and J. Pal (2008), Climate change hotspots in the United States, Geophysical Research Letters, 35(16), doi:10.1029/2008GL035075.

Druyan, L. M. et al. (2010), The WAMME regional model intercomparison study, Climate Dynamics, 35(1), $175-192$.

Evans, J.P. (2009), Global warming impact on the dominant precipitation processes in the Middle East, Theoretical and Applied Climatology, 99(3), 389-402.

Evans, J. P. (2009a), 21 st century climate change in the Middle East, Climatic Change, 92(3-4), 417-432.

Evans, J. P., and M. F. McCabe (2010), Regional climate simulation over Australia's Murray-Darling basin: A multitemporal assessment, J. Geophys. Res., 115(D14114), doi:10.1029/2010JD013816.

Evans, J.P., R.J. Oglesby and W.M. Lapenta (2005), Time series analysis of regional climate model performance, Journal of Geophysical Research D: Atmospheres, 110(4), 1-23.

Evans, J.P., R.B. Smith and R.J. Oglesby (2004), Middle East climate simulation and dominant precipitation processes, International Journal of Climatology, 24(13), 1671-1694.

Foley, A. (2010), Uncertainty in regional climate modelling: A review, Progress in Physical Geography, 34(5), 647-670, doi:10.1177/0309133310375654.

Giorgi, F., C. Jones, and G. R. Asrar (2009), Addressing climate information needs at the regional level: the CORDEX framework, WMO Bulletin, 58(3), 175-183.

IPCC (2007), Climate Change 2007: The Physical Science Basis, edited by S. Solomon, edited by, D. Qin and edited by, M. Manning, edited by , Z. Chen, edited by, M. Marquis, edited by , K.B. Averyt, edited by , M. Tignor, edited by , H.L. Miller, Cambridge University Press, Cambridge, United Kingdom. 
Jones, R., S. Westra, and A. Sharma (2010), Observed relationships between extreme sub-daily precipitation, surface temperature, and relative humidity, Geophysical Research Letters, 37, doi:10.1029/2010GL045081.

Kendon, E., R. Jones, E. Kjellstrom, and J. Murphy (2010), Using and Designing GCM-RCM Ensemble Regional Climate Projections, Journal of Climate, 23(24), 6485-6503, doi:10.1175/2010JCLI3502.1.

Kostopoulou, E., K. Tolika, I. Tegoulias, C. Giannakopoulos, S. Somot, C. Anagnostopoulou, and P. Maheras (2009), Evaluation of a regional climate model using in situ temperature observations over the Balkan Peninsula, Tellus, Series A: Dynamic Meteorology and Oceanography, 61(3), 357-370.

Lenderink, G., and E. Van Meijgaard (2008), Increase in hourly precipitation extremes beyond expectations from temperature changes, Nature Geoscience, 1(8), 511-514, doi:10.1038/ngeo262.

Mariotti, A., N. Zeng, J. Yoon, V. Artale, A. Navarra, P. Alpert, and L. Li (2008), Mediterranean water cycle changes: transition to drier 21 st century conditions in observations and CMIP3 simulations, Environmental Research Letters, 3(4), doi:10.1088/1748-9326/3/4/044001.

Mearns, L. O., W. J. Gutowski, R. Jones, L.-Y. Leung, S. McGinnis, A. M. B. Nunes, and Y. Qian (2009), A regional climate change assessment program for North America, EOS, 90(36), 311-312.

Meehl, G. A., C. Covey, T. Delworth, M. Latif, B. McAvaney, J. F. B. Mitchell, R. J. Stouffer, and K. E. Taylor (2007), The WCRP CMIP3 multimodel dataset - A new era in climate change research, Bull. Amer. Meteor. Soc., 88(9), 1383-1394.

Rummukainen, M., J. Raisanen, B. Bringfelt, A. Ullerstig, A. Omstedt, U. Willen, U. Hansson, and C. Jones (2001), A regional climate model for northern Europe: model description and results from the downscaling of two GCM control simulations, Clim. Dyn., 17(5-6), 339-359.

Salon, S., G. Cossarini, S. Libralato, X. Gao, C. Solidoro, and F. Giorgi (2008), Downscaling experiment for the Venice lagoon. I. Validation of the present-day precipitation climatology, Climate Research, 38(1), 3141.

Smith, I., and E. Chandler (2010), Refining rainfall projections for the Murray Darling Basin of south-east Australia-the effect of sampling model results based on performance, Climatic Change, 102(3-4), 377-393, doi:10.1007/s10584-009-9757-1.

Solman, S.A., M.N. Nuñez and M. Cabré (2008), Regional climate change experiments over southern South America. I: Present climate, Climate Dynamics, 30(5), 533-552.

Tebaldi, C., L. Mearns, D. Nychka, and R. Smith (2004), Regional probabilities of precipitation change: A Bayesian analysis of multimodel simulations, Geophysical Research Letters, 31(24), doi:10.1029/2004GL021276.

Tebaldi, C., R. Smith, D. Nychka, and L. Mearns (2005), Quantifying uncertainty in projections of regional climate change: A Bayesian approach to the analysis of multimodel ensembles, Journal of Climate, 18(10), 1524-1540. Uppala, S. M., D. Dee, S. Kobayashi, P. Berrisford, and A. Simmons (2008), Towards a climate adapt assimilation system: status update of ERA-Interim, ECMWF Newsletter, 115, 12-18.

van der Linden, P., and J. Mitchell (Eds.) (2009), ENSEMBLES: Climate change and its impacts. Summary of research and results from the ENSEMBLES project, Met Office Hadley Centre, Exeter, UK.

Vavrus, S., D. Waliser, A. Schweiger, and J. Francis (2009), Simulations of 20th and 21st century Arctic cloud amount in the global climate models assessed in the IPCC AR4, Climate Dynamics, 33(7-8), 10991115, doi:10.1007/s00382-008-0475-6. 